(This is a pre-print text)

\title{
THE REGRESS-PROBLEM: A REPLY TO VERMAZEN*
}

Carlos J. Moya. University of Valencia (carlos.moya@uv.es)

In his interesting paper 'Carlos Moya's Regress-Problem', ${ }^{1}$ Bruce Vermazen advances criticisms of some points I made in my book The Philosophy of Action: An Introduction. ${ }^{2}$ Vermazen's criticisms are deep and subtle, and I am grateful to him for making them. They reveal some weaknesses in my work, though I think these weaknesses are fewer and less serious than he seems to suppose, or so I will try to show.

Vermazen's comments are restricted to the problem of regress. The title of Vermazen's paper seems to imply that my exposition of this problem is a bit idiosyncratic, and this implicature becomes more explicit when he holds that I give three different versions of it and that in none of them the problem is exactly a problem of regress. Moreover, he holds that my solution to this problem is on a par with those advanced by the views I oppose to: both the former and the latter can solve the (my) second version of that problem but fall prey to the third.

I will attempt to argue, against these criticisms, that there is only one version of the problem, namely the second in Vermazen's classification; that this version of the problem is not idiosyncratic, but can be found in some of the authors I discuss, especially in McCann, and that the views I criticize, unlike my own proposal, cannot solve this problem. I shall also say something about Vermazen's suggestion that there is no proper infinite regress involved in any of the versions, but at most the threat of a regress. Before going to all that, however, I shall try to say a couple of things about the context in which the regress problem should be understood.

When we try to determine what we, as agents, contribute to what we ordinarily call an action of ours, we may discover, with some surprise, that our supposed contribution tends to fade away, swallowed by a flow of causally related happenings. Agency is notoriously elusive. As Zeno Vendler puts it: 'In raising my arm on set purpose, I do not cause my arm to go up: it goes up because some muscles contracted, and this because some neurons fired, and this because... etc.' ${ }^{3}$ Vendler's proposal is that the agent is a transcendental self, but if we do not follow this path, as I

\footnotetext{
* Research for this paper has been funded by the Spanish Government's DGICYT as part of the project PB93-1049C03-02. My thanks to this institution for its generous help and encouragement.

1 This journal.

2 Polity Press/B. Blackwell Inc., Cambridge, 1990.

3 Z. Vendler, The matter of minds, Clarendon Press, Oxford, 1984, p. 119.
} 
think we should not, this sort of reflection is likely to generate scepticism about the existence of actions beyond sequences of happenings. The regress-problem is part of this context of puzzles concerning the elusiveness of agency and scepticism about actions.

How does this problem arise and what exactly is it? It is natural to think of an action as a causing or bringing about of non-actional events by an agent. Danto, McCann, O'Shaughnessy and Hornsby agree that many actions can be so conceived. To kill someone, for instance, is to bring about his death. Now the occurrence of this person's death is necessary, though not sufficient, for an action of the kind 'killing someone' to take place. This death is what McCann calls a result of the killing: 'Results... are events which are necessary for those actions whose results they are. But... they are never sufficient for those actions' ${ }^{4}$ What must be added to this necessary condition to have also a sufficient one? This is what McCann calls 'the result-problem': What makes that death into the result of an action of killing? Since the killing logically (or semantically, as Vermazen aptly says) implies the death, we cannot say that it is the fact that this death is caused by a killing: no killing without a death. (I leave the reader to provide a statement of all this in terms of sentences.) We need to find a causally more basic action that has the death as a causal consequence and so makes it into a result of the action of killing. Shooting that person is a plausible candidate. Can we say, then, that the death was a causal consequence of an action of shooting, and so a result of a killing? Strictly speaking, the death was caused by the bullet's entering that person's body. This person would have died even if this latter event had not been the result of an action of shooting. This means that we have to show that the bullet's entering the body is, in turn, a result of the shooting by finding an action, somehow different from shooting, that has that event as a causal consequence. Pulling the trigger is a plausible candidate. However, pulling the trigger raises the same sort of problem as shooting. Strictly speaking, the shot was caused by the trigger's movement. The shot would have taken place even if the trigger's movement had not been a result of an action of pulling the trigger. So, we still have to show that the trigger's movement was a result of an action of pulling the trigger. We need, then, an even more basic action which, if it also has an associated result, will only take us one step back. This is why McCann rejects basic actions in Danto's sense, namely (certain) bodily movings, as a solution to the regress-problem. Basic actions in Danto's sense have results. The result of moving my finger, for instance, in my finger's movement. Unless we find an action with no result, which causes the result of the action at the next level, we are entering an infinite regress, as McCann himself points out, for 'one would have to bring about an infinite series of further changes in order to bring about any change or set of changes at all. ${ }^{5}$ To

\footnotetext{
${ }^{4}$ H. McCann, 'Volition and basic action', Philosophical Review 83 (1974), p. 452.

5 Ibid., p. 456.
} 
say this is to say that we, as agents, could not bring about any change, that we do not act at all. The change would take place, but it would only be a link of a potentially infinite chain of causally related happenings.

Now I think that this exposition of the problem of regress, based on McCann's resultproblem, is roughly equivalent to what Vermazen calls my second version of this problem (pages 12-13 of my book.), ${ }^{6}$ with logically implied or essentially involved happenings substituted for results. I shall use both expressions interchangeably in this paper. I contend that this is in fact the only version of the problem (which is equivalent to McCann's) that I have used in the relevant chapters of my book. But what about the first version, in Vermazen's classification? Vermazen is uneasy about the notion of explanation used in this version. According to him, in this version, 'the alleged regress began with a request for an explanation of my arm's moving, not an explanation of my moving my arm.' But the regress- problem, even in McCann's case, also contains the request for an explanation of my arm's moving, not of my moving the arm, an explanation of a special kind, namely one that can show the arm's moving to be a result of my moving it. We have this explanation when we find another action that has the arm's moving as a causal consequence, for instance contracting the muscles. This sort of explanation is alluded to in the introduction of my book in requiring a 'factual or informative explanation... of my arm's moving.' If, in the light of subsequent chapters, we read 'explanation' and 'explains' this way, we have a version that, even if sketchy, is equivalent to the second, or so I would think. Even in the introduction this deeper explanatory level is suggested, for the regress-problem is presented there in the context of justifying a strong distinction between actions and happenings. But going beyond that suggestion in an introductory chapter would have required introducing too many technical notions where only a first and intuitive contact with the problems was intended.

Vermazen thinks that, in both versions, the regress is only a threat, not a reality. I have not 'supplied an effective procedure according to which taking each successive step necessitates taking the next step.' The problem is that, in looking for basic actions that can play a role as regressstoppers, we have to stop soon. Behind moving some parts of the body, basic actions in Danto's sense, we can retreat perhaps to contracting muscles, and behind this maybe to firing neurons, if there is such an action. But all these kinds of 'actions' have results. And beyond them there seem to be only further happenings causing those results, none of which can therefore qualify as an action-result. Beyond a certain point, the regress takes us only to further happenings, and of these there can be a potentially infinite chain.

\footnotetext{
6 See my The Philosophy of Action, pp. 12-13.
} 
According to McCann's and O'Shaughnessy views, proper basic actions, capable of stopping the regress, are mental acts, volitions or tryings. (Hornsby insists, instead, on the physical nature of her 'tryings'.) I hold that, if these acts are in fact purely mental, it is hard to see how they can cause the result of the next action in the scale. They face the problem of Cartesian interactionism. So I think, taking into account McCann's and O'Shaughnessy's own explanations of the nature of these acts, that they have to be physical and so they have to involve physical happenings. Do they involve results, i.e., happenings of specific kinds essentially or logically involved in them? Vermazen thinks I have not shown that they do. And here is where, according to Vermazen, I relax the requirement of a logical implication between (a description of) an action and (a description of) a happening of a specific kind, turning that relation into a factually necessary one and so switching to the third, ontological (instead of logical) version of the regress-problem. According to this version, what we need to stop the regress are actions that do not involve any physical happenings, not just results, that is, happenings whose occurrence is logically necessary for some actions to be performed. This is a strong criticism, for if I really make this requirement, my own solution would not be able to meet it. This is in fact what Vermazen objects to it. However, it would be close to incoherent that I made such a request, for this would lead me to ask for purely mental acts, of the sort I rejected by saying that they raised the problem of Cartesian interactionism.

Do I really hold this third version of the regress problem? I agree that it may appear that I do. In using some expressions, I may have given the occasion to think that I have relaxed the logical (or semantic) connection requirement. And Vermazen's subtle insight has not overlooked these clues. I still think, however, that this third version is only an appearance. Let me try to justify this.

The regress-problem, in its second version, is a problem about actions as belonging to action-kinds. An action has a result as belonging to a kind and having a corresponding description: for a particular act to belong to the action-kind 'raising an arm', a happening of the kind 'an arm's rising' has to take place. Unless a happening having this description occurs, no action of the corresponding type has been performed. So, a solution to the regress-problem can only be found if action-kinds can be identified whose tokens do not require happenings of specific types to occur. My solution to this problem consisted in identifying such action-kinds, a common trait of them being their necessarily intentional character.

What about volitional theories? Let us consider O'Shaughnessy's 'tryings' first. I insisted on the fact that there is, in O'Shaughnessy's theory, a conflation of different senses of the word 'trying', namely an ordinary and a technical sense. In its ordinary sense, 'trying to $x$ ' refers to an action $y$ that the agent is performing in order to $x$. The values that ' $y$ ' takes are not fully determined by the values of ' $x$ '. So, one can, for instance, try to start a car by performing actions belonging to several 
action-kinds: turning the key, pushing the car, and so on. Suppose that I am turning the key in order to start the car. Under the description 'turning the key', this action has a result, namely the key's turn. But under the description 'trying to start a car' it has no results. This description is not logically committed to the truth of a statement describing a specific kind of happening. Does this mean that tryings do solve the regress-problem? No, because 'trying', in its ordinary sense, does not refer to an action-kind. It is, so to say, an intentionality index. Whatever one is doing that is truly described as 'trying to $x$ ', one is doing that with the intention to $x$. But there is nothing in common, except this intentional character, between trying to start a car, trying to open a window and trying to buy a house.

However, this ordinary sense of 'trying', though lurking behind O'Shaughnessy's proposal and responsible for many of its apparent virtues, is not the sense intended by him. He wants 'trying' to be an action-kind term, a term whose extension contains particular acts of the same kind. Whenever one performs an action of the kind $x$ there is a particular act of the kind conveyed by 'trying to $x$ '. I insisted on the fact that, in this technical sense, ' $x$ ' can only have as values bodily movings, for, if ' $x$ ' can take any value, it is the ordinary sense of 'trying' that is being used and then trying to $x$ cannot be an action-kind. But then 'trying' has to refer to a physical action-kind (otherwise it falls prey to Cartesian interactionism), say to starting to move (or maybe to firing neurons), and these action-kinds have results. I spoke about tryings involving physical happenings (so giving the impression that I relaxed the logical relation requirement) owing to the fact that nothing was said about the specific action-kind that trying (in the technical sense of this term) was supposed to be identical to. Once a specification is forced, the regress-problem (in its second version) arises once again. That it was this second version that I had in mind can be seen in the following criticism of O'Shaughnessy's view: '... trying is just moving, and moving implies logically that something moves.' ${ }^{7}$

Something fairly similar could be said about Hornsby's tryings. Unlike O'Shaughnessy, Hornsby explicitly says that tryings are physical acts. Describing an action as an event of trying to act is a basic description, not committed, according to Hornsby, to happenings such as body's movings or muscles' contractings. This lack of commitment, I think, points clearly to Hornsby's wish to prevent her tryings from having results. Trying to act, according to her, is a physical act that occurs inside the body and that causes a contraction of the muscles and a movement of the body. But if tryings are internal physical acts that cause these happenings, what kind of acts can they be? We are entitled to ask for a specification, for, as pointed out, 'trying' is used in a technical

\footnotetext{
7 Ibid., p. 26.
} 
sense: tryings have the indicated properties. A plausible answer can be that they are acts of making neurons fire. But these acts have results, namely the neurons' firing.

As for McCann's volitions, they are free from results by stipulation, as Vermazen points out. But two points are in order. First, we are entitled to be sceptical about the referents of McCann's term 'volitions', and I have given reasons for such scepticism in my book. Second, if we want referents for this term and if we take into account some of the traits McCann himself ascribes to volitions, these can be plausibly interpreted in terms similar to O'Shaughnessy's or Hornsby's tryings (or else face the problem of interactionism), and so interpreted they have results after all.

So, it is the second version (in Vermazen's classification) of the regress-problem that tryings and volitions cannot solve. My own candidates for regress-stoppers, in turn, can solve this version, as Vermazen concedes himself, in that they are described at the right level, namely as ordinary action-kinds such as marrying, voting or bidding.

The regress-problem was supposed to be solved by looking for basic actions, bodily movements in Danto's case, volitions in McCann's, tryings in O'Shaughnessy's and Hornsby's. My own proposal for solving this problem has a certain touch of irony, in that it suggests that the proper basic actions (as regress-stoppers) are as sophisticated as marrying, voting or bidding. This irony, however, points to the suggestion that agency, as far as it is related to freedom and responsibility, is less connected to bodily movements than to norms and commitments in a shared, social world. ${ }^{8}$

\footnotetext{
${ }^{8}$ I am grateful to Bruce Vermazen for his comments on an earlier draft of this paper.
} 